\title{
Role of Compatibilizer on Morphological and Mechanical Properties of Low Cost Polypropylene/Wood Flour Composites
}

\author{
Netra L. Bhandari ${ }^{1,2}$, Sabu Thomas ${ }^{3}$, Chapal K. Das ${ }^{3}$, Rameshwar Adhikari ${ }^{\text {1, * }}$ \\ ${ }^{1}$ Central Department of Chemistry, Tribhuvan University, Kirtipur, Kathmandu, Nepal \\ ${ }^{2}$ Department of Chemistry, Tri-Chandra Campus, Tribhuvan University, Kathmandu, Nepal \\ ${ }^{3}$ School of Chemical Sciences, Mahatma Gandhi University, Kottayam, Kerala, India \\ ${ }^{4}$ Materials Science Centre, Indian Institute of Technology (IIT), Kharagpur, India \\ Email: nepalpolymer@yahoo.com
}

\begin{abstract}
Wood flour (WF) reinforced polypropylene (PP) composites were studied with special attention to morphology and mechanical properties of the composites and the effectiveness of chemically modified fillers to improve their mechanical properties. The composites of polypropylene with neat wood flour and treated wood flour of Sorea robusta in different proportions were prepared by melt mixing followed by compression molding. Maleic anhydride grafted polypropylene (MA-g-PP) was used as compatibilizer. The samples were characterized by Fourier Transform Infrared (FTIR) spectroscopy, Scanning Electron Microscopy (SEM), tensile testing, and water absorption testing. The results show that the alkali treated WF is more compatible with PP matrix than the neat one and the effects are reflected in the morphological and mechanical properties of the composites. The compatibilizer has been found to play key role to enhance the filler-matrix interfacial interactions.
\end{abstract}

Keywords: Wood Flour Composites, Mechanical Properties, Compatibilizer

\section{Introduction}

Natural fiber composites (NFCs) and wood polymer composites (WPCs) based on polyolefin (such as polyethylene, PE; polypropylene, PP etc.) have gained increasing interest over the last two decades, both in the scientific community and in industry ${ }^{1}$. The composite materials offer a wide variety of mechanical, physical, and optical, properties usually better than the individual components ${ }^{2}$. WPCs are generally cheaper, easily processable, have relatively better dimensional stability, and lower density in comparison to mineral fillers. These are environmentally friendly and economically viable ${ }^{3}$ in addition. In WPCs, different types of wood flour are used as fillers. The properties of WPC's basically depend on the type of flour, particle size, chemical treatment and the nature of thermoplastic polymers chosen as matrix ${ }^{4}$. Polypropylene (PP), polyethylene (PE), polyvinyl chloride (PVC), polystyrene (PS), polyethylene terephthalate (PET) and several blends and copolymers are commonly used polymer matrices. Most of the composites are biodegradable to some extent, but nowadays, works have been focused towards the development of totally biodegradable composites ${ }^{2,4}$.

In wood flour, cellulose is the major constituent, a biopolymer produced in nature by photosynthesis, which is associated with lignin and other polysaccharides such as hemicellulose ${ }^{5-7}$. The cellulose chains

\section{* Corresponding author}


are organized in crystalline fibrils by inter- and intra-molecular hydrogen bonding and forms the microfibrillar bundles which are compactly held to each other by means of hemicellulose where the lignin provides the mechanical strength ${ }^{2,8,9}$.

The WPCs are processed with similar technologies that are used in the plastic processing industries like extrusion, injection molding, and compression ${ }^{10}$. The choice of wood flour as filler and the polymer as matrix determines the process to be applied. The dehydration of the wood, degree of permissible moisture content, size of particles and nature and content of the additives are the decisive factors governing the properties of the WPCs ${ }^{10,11}$.

The most important drawback in designing and developing natural fiber reinforced polymer composites is the problem of chemical incompatibility between hydrophilic natural fibers and the hydrophobic thermoplastic matrices. .

The incompatibility at the interface results in reduced adhesion which limits the reinforcement potential of natural fibers exfoliation to the full extent, especially for short fibers and particles. The fibermatrix interface performance of the composite can be improved either by increasing the aspect ratio of the fiber or by increasing the capability for the stress transfer at the interface (fiber matrix interaction). Numerous strategies have been made to improve the interaction at the fiber-matrix interface ${ }^{1,2}$.

For polypropylene based WPCs, the hydrophilic properties of the reinforcement fibers or particles are an additional reason to attempt improvement of the fiber matrix interaction (compatibilization). Usually the hydrophobic matrices can protect the reinforcements from humidity and the potential can only be fulfilled if the fibers or the particles are dispersed evenly throughout the matrix and if they are covered with matrix polymer most tightly. A gap between the matrix and reinforcement, as it can often be observed in uncompatibilized WPCs, acts like a pathway for humidity into the material. Absorbed moisture leads to dimensional changes, which is problematic for almost all applications. Furthermore it causes a reduction of mechanical performance, of the product lifetime, especially in combination with weathering ${ }^{1,2}$.

The fiber-matrix interaction can be improved either via the fiber, usually by modifying its surface, or via the matrix, usually by employing additives called coupling agents. Furthermore, the combination of those two approaches (i.e., the use of pretreated fillers together with matrix-based coupling agents) has been reported as well. The mechanical, morphological and thermal properties of different wood flour (sisal, jute, flex, hemp, kenaf, bamboo, oil palm) of various size and concentration have been studied and reviewed in detail ${ }^{4,5,14-16}$.

The aim of this research is to study the role of MA-g-PP in polypropylene/wood flour composites prepared by neat and alkali treated wood flour of Sorea robusta (directly collected from the carpentry) and its effect on morphology and mechanical behavior. The composites were analyzed by FTIR, microscopy, DMA tensile testing and water absorption.

\section{Experimental Methods}

\section{Materials}

Fillers: The fillers used in this research was the wood flour of Sorea robusta (local name: Saal) directly collected from the carpentry in Kathmandu. The flour was sun dried for 6 days and sieved with $350 \mu \mathrm{m}$ mess to get the uniform particles size.

The wood flour was dipped in $4 \%(\mathrm{w} / \mathrm{v})$ sodium hydroxide solution in water for 8 hours, neutralized with acetic acid, washed many times with water and finally oven dried at $90{ }^{\circ} \mathrm{C}$ for 12 hours 9 . The objective of chemical treatment was to remove lignin and hemicelluloses from the wood flour The reaction involved in the chemical treatment can be represented as in equation (1). 


$$
\text { Wood }-\mathrm{OH}+\mathrm{NaOH} \longrightarrow \text { Wood } \longrightarrow \mathrm{O}^{-} \mathrm{Na}^{+}+\mathrm{H}_{2} \mathrm{O}
$$

Matrix: The matrix polymer used was the isotactic polypropylene (iPP), a commercial homopolymer (Moplen PP562N) of Basell Chemical Company having molecular weight of 230,000 g/mol and melt flow index (MFI) of $11 \mathrm{~g} / 10 \mathrm{~min}$. The melting point and glass transition temperature of iPP were measured to be $208^{\circ} \mathrm{C}$ and $-8{ }^{\circ} \mathrm{C}$, respectively.

The iPP/wood flour composites (80/20, 60/40 and 40/60 weight ratios) were prepared by melt mixing followed by compression molding. 5 wt.- $\%$ maleic anhydride grafted polypropylene (MA-g-PP; Scona Exelor $\left.{ }^{\mathrm{TM}} \mathrm{PO} 1020\right)$ was used as compatibilizer. The required amount of components was mixed in an internal mixture at $160{ }^{\circ} \mathrm{C}$ with a rotor speed of $50 \mathrm{rpm}$ for 10 minutes. The tensile bars were prepared by compression molding at $160{ }^{\circ} \mathrm{C}$ and 120 bar pressure for 2 minutes.

\section{Characterization techniques}

Fourier Transform Infrared (FTIR) Spectroscopy: FTIR spectra of solid injection moulded samples were recorded in absorbance and transmittance mode using a Bruker Equinox 55 FTIR spectrometer in ATR mode.

Microscopy: Scanning electron microscopy (JSM 6300, JEOL) was used to visualize the structural details of the fracture surface of the samples. The surfaces were sputtered coated with thin gold film to avoid charging and irradiation damage during the SEM observations. The specimens for Optical microscopic investigation were prepared by cutting $20 \mu \mathrm{m}$ thin sections of the composite with the help of a microtome were inspected with Nikon microscope (Nikon 27889) fitted with Sony camera.

Mechanical Testing: The mechanical testing was carried out by using universal tensile machine. Tensile bars having $40 \times 5.1 \times 1.8 \mathrm{~mm}$ size were prepared by compression molding. At least four experiments were performed at a cross head speed of $50 \mathrm{~mm} / \mathrm{min}$ at $23{ }^{\circ} \mathrm{C}$ for each composite sample and the average value was considered for the comparison.

Water Absorption: Water absorption by each composite was determined according to the standard procedure mentioned in the literature ${ }^{18}$. The test specimens were cut from composite sheets, dried at 60 ${ }^{\circ} \mathrm{C}$, cooled and weighed till the constant weight $\left(\mathrm{w}_{1}\right)$ was obtained. The specimens were then immersed in beaker containing distilled water at room temperature. The weight of the test specimen was measured daily for a week, every 2 days for two weeks and finally every 10 days for three weeks. The weight average $\left(\mathrm{w}_{2}\right)$ was calculated for each specimen. The increase in weight $\%$ was calculated by using equation (2).

$$
\% \text { Water Absorption }=\left(w_{2}-w_{1}\right) / w_{1} \times 100
$$

\section{Results and Discussion}

Fig. 1a shows the FTIR spectra of neat and alkali treated wood flour (WF). The alkali treatment of filler was carried out to remove the hemicelluloses and lignin from it. Both neat and alkali treated WF clearly shows their characteristic peaks of cellulose at $3430 \mathrm{~cm}^{-1}, 2920 \mathrm{~cm}^{-1}$ and $1050 \mathrm{~cm}^{-1}$ corresponding to the $\mathrm{OH}$ stretching, $\mathrm{CH}$ stretching and $\mathrm{C}-\mathrm{O}-\mathrm{C}$ stretching peak of pyranose ring structures respectively ${ }^{15}$. 

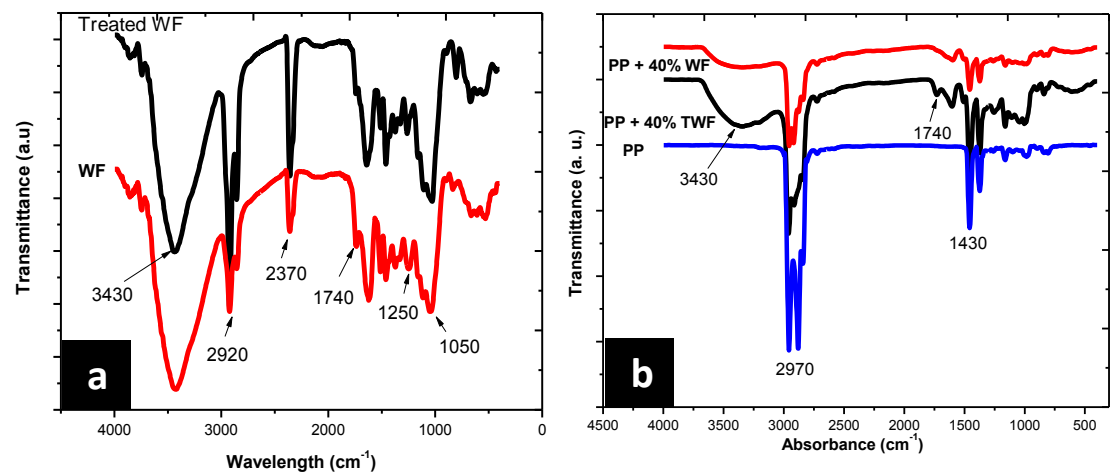

Figure: 1. Fourier transform infrared (FTIR) spectra of: a) Neat WF and treated WF, and b) PP/WF composites (60/40 composition) of neat and treated fibers compared with pure PP.

The strong carbonyl $\left(\mathrm{C}=\mathrm{O}\right.$, stretching) peak at $1740 \mathrm{~cm}^{-1}$ found in neat $\mathrm{WF}$ is absent in alkali treated WF indicating the removal of acetyl group of hemicellulose from the fibers. A group of complex IR absorbance of lignin in finger print region (1500-700 $\mathrm{cm}^{-1}$ ) might be due to stretching of methoxy O$\mathrm{CH}_{3}$, ether $\mathrm{C}-\mathrm{O}-\mathrm{C}$, and $\mathrm{C}=\mathrm{C}$ stretching of aromatic ring containing compounds.

The lignin peaks at $1540 \mathrm{~cm}^{-1}, 1250 \mathrm{~cm}^{-1}$ in neat $\mathrm{WF}$ due to the aromatic $\mathrm{C}=\mathrm{C}$ stretching and aromatic ether $\mathrm{C}-\mathrm{O}-\mathrm{C}$ stretching are much reduced in treated WF due to partial removal of lignin after the alkali treatment ${ }^{17,18}$.

The FTIR spectra of PP/WF composites (60/40 compositions with neat WF and treated WF) are compared with PP in Fig. 1b. The intense peaks at $2970 \mathrm{~cm}^{-1}$ and around $1430 \mathrm{~cm}^{-1}$ are the characteristic of the $\mathrm{CH}$ stretching and $\mathrm{C}_{-} \mathrm{CH}_{3}$ stretching of polypropylene. The peaks are also observed in the spectra of the neat filler and treated filler loaded PP/WF composites. The spectra of the composites shows the peaks corresponding to cellulosic filler $\left(3430 \mathrm{~cm}^{-1}, 1740 \mathrm{~cm}^{-1}, 1430 \mathrm{~cm}^{-1}\right.$ and around $1000 \mathrm{~cm}^{-}$ $\left.{ }^{1}\right)$ and the peaks characteristics of PP $\left(2970 \mathrm{~cm}^{-1}, 1430 \mathrm{~cm}^{-1}\right)$.

The SEM micrograph of the fracture surface of neat PP/WF composites (40/60 composition) (Fig. 2a.) and using MA-g-PP as compatibilizer (Fig. 2b.) show the topography of the fracture surface of the composite. There is practially no difference in the morphology of the two composites except large regions of accumulated fibers implying the poor compatibility at the filler-matrix interface. The interfacial interaction seems to improve in the composite prepared with MA-g-PP as shown in Fig. $2 \mathrm{~b}$ due to the abcence of such pulled out fibers in the micrograph. Supporting results are also observed in optical micrographs of the samples as depicted in Fig. 3.
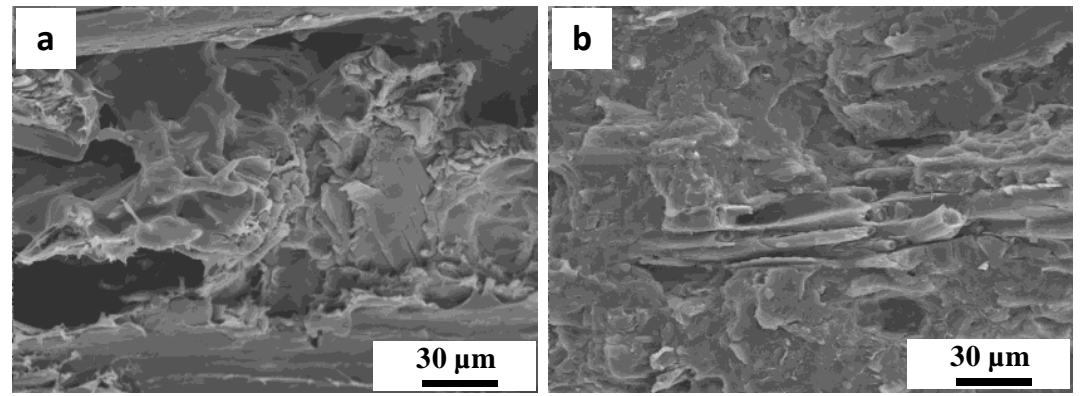

Figure 2. SEM images of PP/WF composites' fracture surface (40/60 composition). a) Uncompatibilized composite, and b) Compatibilized composite. 
Fig. 3 presents the optical micrographs of the PP/WF composite (80/20 composition) in which the composite morphology is depicted. Fig. $3 \mathrm{a}$ and $3 \mathrm{~b}$ are without and with MA-g-PP as compatibilizer, respectively. The sections for optical microscopy were prepared by a microtome at room temperature. The thin sample of the composite was prepared with the help of microtome. During sectioning, the force exerted at the interfacial region causes damage at phase boundary if the compatibility is not sufficient. In Fig. 3a, large voids or the gaps are observed at the fiber-matrix interface (indicated by an arrow), which are not observed in Fig. 3b. This observation implies that the initiation of the deformation starts from the fiber-matrix interface due to weak bonding.
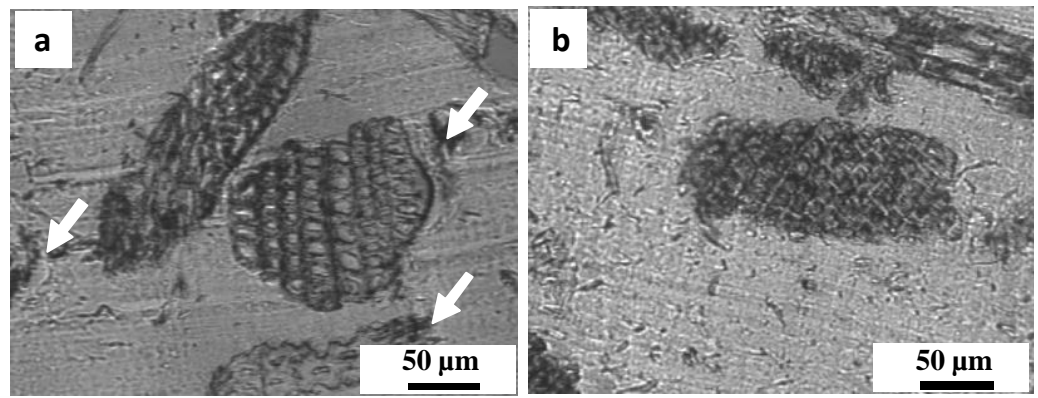

Figure 3. Optical micrographs of PP/WF composites (80/20 composition): a) Uncompatibilized mixture showing void formation at fiber-matrix interface, and b) compatibilized one without voids.

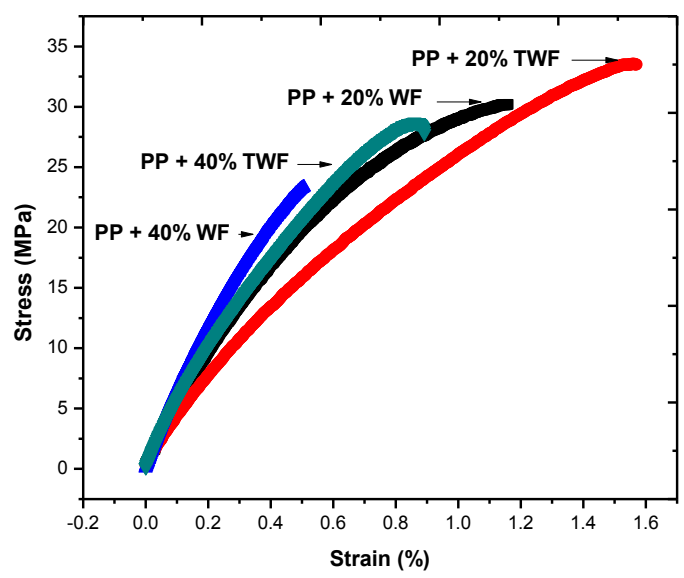

Figure 4. Tensile stress-strain curve of PP/WF composites (80/20 and 60/40 compositions) with neat WF and treated $W F$.

Tensile stress strain curves of $\mathrm{PP} / \mathrm{BF}$ composites (80/20, 60/40 compositions) with neat and alkali treated wood flour are shown in Fig. 4. The strain at break of the composites with neat WF and treated WF are compared. All the samples except pure iPP were broken below $2 \%$ strain. The strain of polypropylene goes beyond $150 \%$ (curve is not shown) ${ }^{14}$. The mechanical properties of the composites with respect to strain at break have decreased as the flour content is increased.

The elongation at break has improved in alkali treated WF composites than the neat WF composite. The effect is significant in $20 \mathrm{wt} .-\%$ filler composite. The yield stress (and thus the load bearing capacity of the composite) was also found to increase in the composites with treated WF as compared to the neat WF composites. It implies that the mechanical strength of the treated filler loaded composites have better tensile properties than the neat flour loaded composites for the same compositions. 
The percentage of water absorption of PP/WF composites (80/20, 60/40 and 40/60 compositions) compared with the pure iPP is represented in Fig. 5. The curve PP/WF represents the composites without compatibilizer. The curves show a clear trend of water absorption by the composites. As the filler content is increased, the extent of water absorption is also increased that may be attributed to the increased cellulose content in the composites. Water is absorbed in the composites only due to the presence of the hydrophilic cellulose in BF. The percentage water absorption in pure PP is almost zero and is represented by straight line in the plot at the bottom in Fig. 5.

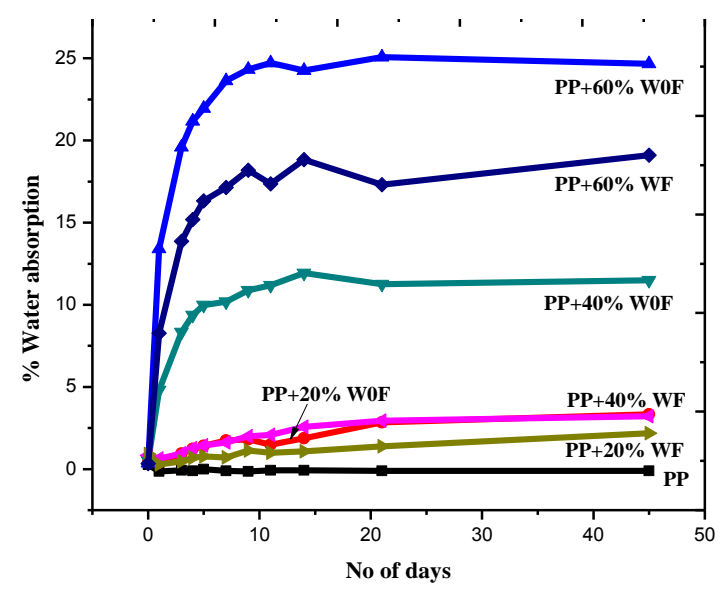

Figure 5. Water absorption of the PP/WF composites (80/20, 60/40 and 40/60 composition) having MA$g-P P(P P / W F)$ and without having $M A-g-P P(P P / W O F)$.

In composites, as the amount of neat WF is increased from 20 to $40 \mathrm{wt}$. $-\%$, the water absorption is also increased by about $10-15 \%$. The water absorption is reduced in the composites prepared by using the MA-g-PP as compatibilizer. The PP/40 wt. -\% of WF composites prepared using compatibilizer has $\%$ water absorption as much as to that of the PP/20 wt. $-\%$ of composite prepared without using the compatibilizer.
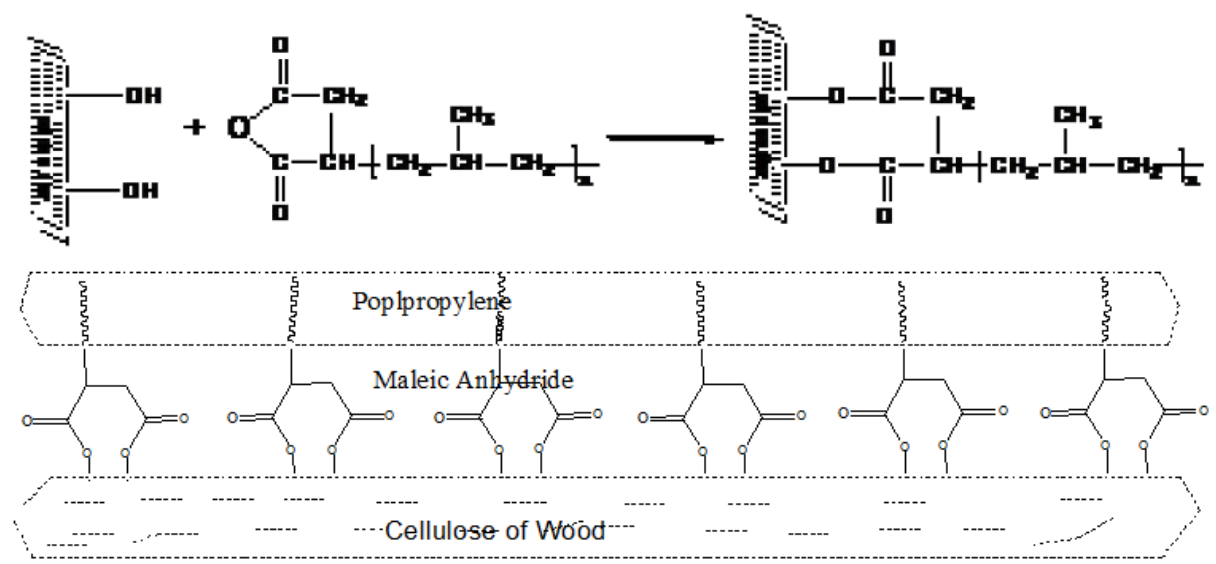

Figure 6: Schematic mechanism of the role of MA-g-PP to improve the filler matrix interaction in PP/WP composites. 
It clearly shows that the PP/WF composites made by using MA-g-PP, the water absorption capacity is much more increased than in the composites prepared without compatibilizer. It clearly indicates that the MA-g-PP helps to improve the filler-matrix interfacial interaction.

From the above results it can be concluded that the MA-g-PP will help to improve interfacial interaction at filler matrix interfaces. The effect of the compatibilizer is pronounced in case of composites prepared by using the treated fillers than in the composites prepared with neat fillers. In case of treated fillers the cellulose microfiber surface is exposed and hence there is an increase in the interfacial interaction. The filler-matrix interfacial interactions can be increased either by the fiber-modifying strategy (e.g., alkali treatment) or by the matrix- modifying strategy (e.g., use of compatibilizer). Both of those processes will help to increase the filler -matrix interfacial interactions either by forming a covalent bond or via the hydrogen bonding.

A simple schematic and mechanistic illustration of the role of maleic anhydride grafted polypropylene for making wood flour reinforced PP composites is shown in Fig. 6. The effect of filler matrix interfacial interaction was clearly observed in surface morphology, fracture surface topography, tensile mechanical behaviour as well as in water absorption.

\section{Conclusions}

Polymer composites based on isotactic polypropylene (iPP) and wood flour of Sorea robusta collected directly from the carpentry were fabricated via melt mixing with and without maleic anhydride grafted polypropylene (MA-g-PP), the compatibilizer. The filler used was either neat or that treated with alkali solution. The samples were characterized by different techniques such as infrared (IR) spectroscopy, electron microscopy, tensile testing and water absorption testing. The alkali treated wood flour has been found to be more compatible with iPP in the compatiblized composites. It might have resulted from the increased fiber-matrix interfacial interaction due to larger exposure of the cellulose microfibrillar surfaces. As a result, the physical properties of the composites with treated fibers were found to be superior . In general, water absorption capacity of the composites was found to increase with increasing filler content. In case of the compatiblized composites, however, the increment was found to be lower in the composites prepared without using the grafted polypropylene. The observation can be attributed to the enhanced compatibility of the treated wood flour with iPP matrix.

The materials would be useful for high load bearing applications. As this approach of composites preparation is economically viable as well as environmentally benign, such kind of works is very important in Nepal because of easy availability of wood flour from the local natural resources.

\section{Acknowledgements}

The authors acknowledge research group of Prof. Goerg H. Michler (Martin Luther University HalleWittenberg, Halle/Saale, Germany), in particular Ms. Cornelia Becker, for providing the laboratory facilities to conduct microscopic experiments. German Science Foundation (DFG) is thanked for supporting the Research Stay of NLB at Halle.

\section{References}

1. S. Sobczak, O. Bruggemann R. F. Putz, J. Appl. Polym. Sci., 2013, DOI: 10.1002/app.36935.

2. A. K. Bledzki and V. E. Sperber, $7^{\text {th }}$ Global WPC and natural fiber composites congress and exhibition. Scientific Presentations 2008, Kassel, Germany.

3. A. K. Bledzki and J. Gassan. Prog. Polym. Sci., 1999, 24, 221. 
4. G. Bogoeva-Gaceva, M. Avella, M. Malinconico, A. Buzarovska, A. Grozdanov, G. Gentile, M. E. Errico, Polym. Comp., 2007, 98.

5. D. N. Saheb and J. P. Jog, Adv. Polym. Tech., 1999, 18, 351.

6. G. Kalaprasad, B. Francis, S. Thomas, C. R. Kumar, C. Pavithran, G. Groeninckx, S. Thomas, Polymer International, 2004, 53, 1624.

7. Y. Li, Y. W. Mai and L. Ye, Comp. Sci. Tech., 2000, 60, 2037.

8. M. J. John, R. D. Anandjiwala, Polym. Comp., 2008, 29, 187.

9. S. Kumar, V. Choudhary, R. Kumar, J. Therm. Anal. Calorim., 2010, 102, 751.

10. L. H. Sperling, Introduction to physical polymer science, $4^{\text {th }}$ ed. 2006. Wiley Inter Science Publication, New York, USA. p. 477.

11. S. Fakirov, Handbook of engineering biopolymers: homopolymers, blends, and composites, 2007, Hanser Publishers, Munich.

12. R. M. Rowell, Handbook of wood chemistry and wood composites, 2005 (R. M. Rowell, Ed.), Taylor \& Francis, CRC Press, USA.

13. S. M. B. Nachtigall, G. S. Cerveria, S. M. L. Rosa, Polymer Testing, 2007, 26, 619.

14. R. Adhikari, N. L. Bhandari, H. L. Hai, H. J. Radusch, G. H. Michler, M. R. Garda, J. M. Saiter, Macromol. Symp., 2012. 315, 24.

15. S. K. Chattopadhayay, R. K. Khandal, R. Uppaluri, K. Ghoshal, J. Appl. Polym. Sci., 2011, 119, 1619.

16. A. Bourmaud, C. Baley, Polym. Degrad.Stab., 2007, 92, 1034.

17. U. P. Agarwal, R. S. Reiner, J. Raman Spectroscop., 2009, 40, 1527.

18. H. Yang, R. Yan, H. Chen, D. H. Lee, C. Zheng, Fuel 2007, 86, 1781. 